\title{
Deployment of plug-in electric vehicles in China and the USA: issues and opportunities, foreword
}

\author{
Michael Wang ${ }^{1} \cdot$ Hewu Wang ${ }^{2}$
}

Received: 4 February 2020 / Accepted: 24 April 2020 / Published online: 19 May 2020

(C) This is a U.S. Government work and not under copyright protection in the US; foreign copyright protection may apply 2020

Keywords Plug-in electric vehicles · Market potentials · The United States of America · China

Plug-in electric vehicles (PEVs), including battery electric vehicles (BEVs) and plug-in hybrid electric vehicles (PHEVs), have been promoted globally for their emission reductions and energy conservation. In addition to financial incentives for PEVs in many countries (Stephens et al. 2018), emission and energy regulatory systems provide additional incentives for PEVs in the USA, Europe, and China (European Union 2014; Innovation Center for Energy and Transportation 2019; U.S. EPA and NHTSA 2012). These incentives, together with PEV technology advances and cost reductions, have caused PEV sales to grow exponentially in many countries and global regions; PEV stocks totaled more than 5 million by the end of 2018 (Fig. 1). The International Energy Agency (2019) projects that PEV sales will grow even more quickly through 2030 to reach a total global PEV stock of 130 million to 250 million.

PEVs, however, still constitute only a small fraction of total vehicle sales. In 2018, PEV sales in China, the country where PEV sales are growing the fastest, made up only $4.5 \%$ of its total vehicle sales. In the USA, PEV sales were less than $2 \%$ of all vehicle sales. PEVs, especially BEVs, face challenges such as high initial vehicle costs caused by high battery costs, short driving ranges due to low battery energy density, and limited recharge infrastructure. The Clean Vehicle Consortium of the Clean Energy Research Center, which is jointly funded by the U.S. Department of Energy and China Ministry of Science and Technology, has been conducting research to address these challenges (see https://cerc-cvc.anl.gov/ for details).

Michael Wang mqwang@anl.gov

Hewu Wang

wanghw@tsinghua.edu.cn

1 Systems Assessment Center, Energy Systems Division, Argonne National Laboratory, Lemont, IL 60439, USA

2 School of Vehicle and Mobility, Tsinghua University, Beijing 100084, China 
This special issue is a collection of papers from this and other research efforts to address opportunities and challenges of PEV development in the USA and China. Gan et al. projected Chinese passenger vehicle stock with a Chinese vehicle fleet model they developed. They projected that the Chinese passenger car stock could reach 400 million by 2040 if the current growth pattern of car ownership continues. At present, about 10 Chinese cities have car sales restriction policies in place to tackle urban traffic congestion. Without these policies, Gan et al. estimated that Chinese passenger car stock could be even higher: 455 million by 2040. On the other hand, Chinese car stock levels could be at 280 and 350 million by 2040 if annual car sales are capped at 20 and 25 million, respectively.

To better assess travel demand and PEV usage, Ou et al. examined Chinese vehicle use intensity and travel patterns. They estimated annual vehicle kilometers traveled per passenger vehicle, as well as vehicle daily distance patterns by vehicle class and geographic region, within China. Using data from a survey of private passenger vehicles, they concluded an average annual vehicle kilometers traveled of $12,380 \mathrm{~km}$ with $95 \%$ probability ranging from 5490 to $28,580 \mathrm{~km}$. The $\mathrm{Ou}$ et al. study revealed that southern Chinese vehicles have higher usage intensity, and vehicles in small cities generally have higher vehicle usage intensity than in big cities, except for tier 1 cities where usage intensity is the highest. The average daily commuting distance ranges from 21 to $28 \mathrm{~km}$, and $99 \%$ of the daily driving distance is no more than 88 to $112 \mathrm{~km}$, depending on the region.

Hao et al. examined the effects on PEV market of government policies, test procedures, customer acceptance, and PEV performance between China and the USA. Although sales in China are higher than those in the USA, the USA has higher PEV ownership per 1000 people: 2.3 versus 0.81 in China. The most popular BEVs are small in China, but long-range and midsize in the USA. However, Chinese electric sport utility vehicles are emerging as top sellers. The cost of PEV batteries in both countries is close to $\$ 210-\$ 220 / \mathrm{kWh}$. Hao et al. also found that China has more extensive charging infrastructure than the USA does; the ratio of PEVs to public chargers is 9.0 in China, versus 17.9 in the USA. However, it is well known that the USA has more extensive home recharge availability than China does.

A key reason PEVs are being promoted globally is their potential emission reductions and energy conservation benefits. Although several regulations treat BEVs as zero-emission vehicles, their true environmental effects need to be examined on a life cycle basis. Three papers in this special issue address life cycle analyses (LCAs) of PEVs versus conventional vehicles.

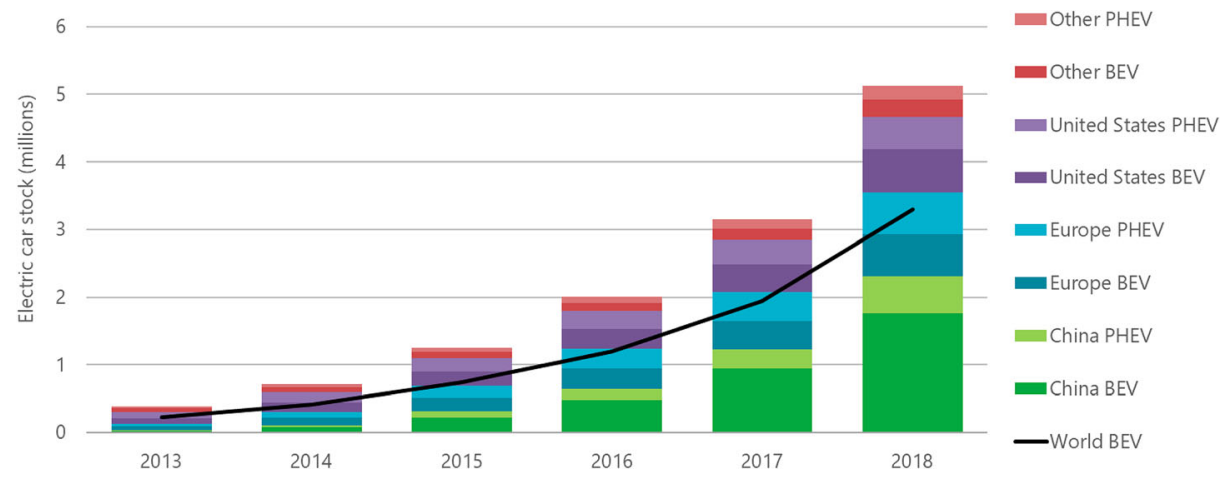

Fig. 1 Global plug-in electric vehicle stocks (IEA 2019) 
Zheng et al. conducted a well-to-wheels (WTW) analysis of Chinese BEVs. With up-todate data for energy use and emissions in the electricity generation, emission controls in the power and industrial sectors, and efficiencies and emissions of fuel transportation, they showed that an average electric car in China has 35\% lower WTW greenhouse gas (GHG) emissions than an average gasoline car does. BEVs reduce emissions of volatile organic compounds and nitrogen oxides by $98 \%$ and $34 \%$, respectively, but have comparable or slightly higher emissions of fine particulate matters and sulfur dioxide. The Zheng et al. results show the importance of the transition to clean power sources and electric power plant emission controls in achieving the emission reduction benefits of BEVs. Embodied emissions in batteries are major contributors to BEV emissions.

Kelly et al. conducted an LCA of lithium-ion batteries with cathode of lithium nickel manganese cobalt oxide (NMC), particularly $\mathrm{LiNi}_{1 / 3} \mathrm{Mn}_{1 / 3} \mathrm{Co}_{1 / 3} \mathrm{O}_{2}(\mathrm{NMC111})$, the most popular cathode chemistry now in BEV lithium batteries. They included alumina reduction and nickel refining, along with the production of NMC cathode, battery cells, and battery management systems. Because energy sources for heat and electricity generation are subject to great regional variation, the study examined battery production in the USA, China, Japan, South Korea, and Europe. Their results showed that batteries via a European-dominant supply chain generate $65 \mathrm{~kg}$ $\mathrm{CO}_{2} \mathrm{e}$ of GHG emissions per kilowatt-hour of battery, while those produced via a Chinesedominant supply chain generate $100 \mathrm{~kg} \mathrm{CO}_{2} \mathrm{e} / \mathrm{kWh}$; results for other countries fall between these two values. Furthermore, significant regional differences exist for local pollutants associated with BEV batteries, especially emissions of sulfur oxides related to nickel production.

$\mathrm{Bi}$ et al. applied a life cycle framework to evaluate the synergies of four emerging transportation technologies: wireless charging, shared mobility services, autonomous driving, and BEVs. They demonstrated that combining these four technologies can shorten the payback time of GHG emission burdens for infrastructure and vehicles.

Sustainable PEV market development requires an understanding of consumer purchase behaviors and PEV characteristics. Ouyang et al. studied factors that influence consumer BEV purchase in the Chinese overall market versus in vehicle sales-restricting Chinese cities. They concluded that a PEV sales allowance in vehicle sales-restricting cities is more influential than a purchase subsidy for Chinese consumers. China's national incentive policies for PEVs and the fuel consumption standard disproportionally favor long-range PEVs. However, they tend to have lower energy efficiency, higher purchase and operation costs, and safety concerns.

Xing et al. explored the optimal ranges of BEVs and PHEVs based on daily driving data of conventional gasoline vehicles in Beijing and PHEVs in Shanghai. To minimize the emissions of PEVs while ensuring that daily travel demands are met, Xing et al. showed that the optimal $\mathrm{BEV}$ range is less than $350 \mathrm{~km}$ and the optimal PHEV range is $10 \mathrm{~km}$ in Beijing; the optimal range for PHEVs in Shanghai is less than $30 \mathrm{~km}$. Hao et al. estimated the electricity generated for PHEVs from their onboard engine and offboard grid charging with a grid electric driving ratio (grid-EDR) based on the battery energy variation under real road conditions. PHEVs with higher grid-EDRs demonstrate better fuel economy. By increasing charging frequency for PHEVs with more extensive charging infrastructure, the grid-EDR of PHEVs can be improved and their GHG emissions can be reduced.

Heavy-duty trucks face technical challenges to be electrified. One way to electrify them is through hydrogen fuel cells. To support the deployment of fuel-cell electric trucks, Liu et al. explored US hydrogen refueling infrastructure requirements along major US interstate highway corridors. They developed ramping-up scenarios involving various locations and numbers of hydrogen refueling stations for hydrogen fuel-cell long-haul trucks. They then conducted an 
economic feasibility analysis of fuel-cell heavy-duty trucks by evaluating total ownership costs. They found that when penetration is relatively high (e.g., 10\%), fuel-cell trucks can be competitive to diesel technology in terms of fuel cost and idling cost.

In conclusion, electrification of the transportation sector is key to significantly reducing transportation's GHG emissions. While China and the USA have shown promising paths to the electrification of transportation, various technological, cost, and infrastructure challenges are still being overcome. We hope that the papers in this special issue will offer insights that benefit the electrification of global transportation.

Authors' contribution Michael Wang and Hewu Wang contributed to organization of manuscripts submitted to this Special Issue. M. Wang wrote this manuscript. H. Wang reviewed this manuscript.

Funding information Funding for Michael Wang was provided by the U.S. Department of Energy. Funding for Hewu Wang was provided by China Ministry of Science and Technology.

\section{Compliance with ethical standards}

Conflict of interest The authors declare that they have no conflict of interest.

\section{References}

European Union (2014) Amending Regulation (EC) No 443/2009 to define the modalities for reaching the 2020 target to reduce CO2 emissions from new passenger cars, Regulation (EU) No 333/2014 of the European Parliament and of the Council, Brussels, Belgium, March 11

IEA (International Energy Agency) (2019) Global EV outlook 2019. International Energy Agency, Paris

Innovation Center for Energy and Transportation (2019) China passenger vehicle CAFC-NEV credits research report (2018). Beijing, China

Stephens T, Zhou Y, Burnham A, Wang M (2018) Incentivizing adoption of plug-in electric vehicles: a review of global policies and markets, ANL/ESD-18/7, Energy Systems Division, Argonne National Laboratory, June

U.S. EPA (Environmental Protection Agency) and NHTSA (National Highway Traffic Safety Administration) (2012) 2017 and later model year light-duty vehicle greenhouse gas emissions and corporate average fuel economy standards; final rule. Fed Regist 77(199):62623-63200

Publisher's note Springer Nature remains neutral with regard to jurisdictional claims in published maps and institutional affiliations. 